\title{
Knowledge, attitude and Practices about Biomedical Waste management among Nursing Professionals of SKIMS Medical College Hospital Bemina-A Cross Sectional study
}

\author{
Dr. M Rafiq Mir, Dr. Javid Ahamad, Dr. Ashfaq Ahamad, Dr. Rifat Jan \\ Assistant Prof/Incharge Head Community Medicine SKIMS Medical College Bemina \\ Tutor/Demonstrator Community Medicine SKIMS Medical College Bemina \\ Lecturer Epidemiology SKIMS Medical College Bemina \\ Postgraduate scholar Deptt of SPM Govt Medical College Srinagar
}

\begin{abstract}
Nursing professionals form the backbone of any hospital. Nurses play a vital role in imparting health services in all level viz, protection, prevention, promotion and treatment. Their level of awareness regarding biomedical wastes can go a long way towards safe disposal of hazardous hospital waste \& protect the community from its various adverse effects. In this connection a cross sectional study was done among 50 staff nurses regarding knowledge, attitude and practices regarding biomedical wastes and the results show a higher level of awareness and attitudes as well as practices regarding biomedical waste management except for the injury report which is as low as 30\%. The study highlights the importance of training regarding biomedical waste management needs.
\end{abstract}

Key words: Biomedical waste management, knowledge, Practices

\section{Introduction :}

Health care services produce biomedical waste (BMW), which is defined as waste generated during diagnosis, treatment or Immunization of Human beings or animals or in research activities pertaining thereto or in the production \& testing of biological \& is contaminated with body fluids ${ }^{(1)}$. Majority of this waste $(75-80 \%)$ is noninfectious but $20-25 \%$ of it is hazardous, which is a potential health hazard to health workers, public, flora $\&$ fauna ${ }^{(2)}$.it is estimated that about 0.33 million tones of hospital waste is generated in India \& the waste generation rate ranges from 0.5 to $2 \mathrm{~kg} / \mathrm{bed} / \mathrm{day}^{(3)}$. Though legal provisions (Biomedical Waste(management \& Handling) rules 1998) $)^{(4)}$ exist to decrease the health impact of hazardous waste generated, yet absence of proper waste management, lack of awareness about health hazards, financial \& human resource constraints \& poor control of waste disposal are the most critical problems ${ }^{(5)}$. Although an increased global awareness among health professionals about the hazards \& also appropriate management techniques exist but the level of awareness in India is found to be unsatisfactory ${ }^{(6)}$. Nursing professionals form the backbone of any hospital. Nurses play a vital role in imparting health services in all level viz, protection, prevention, promotion and treatment. Their level of awareness can go a long way towards safe disposal of hazardous hospital waste \& protect the community from its various adverse effects. With this background, the study was conducted to assess the knowledge, attitude \& practices about biomedical waste in nurses of SKIMS Medical college Hospital.

\section{Methodology}

The SKIMS Medical College hospital is a teaching Hospital with bed strength of about 300. Around 115 nurses are working in the hospital in various departments \& around various shifts. A random sample of 50 nurses was taken and a pretested, predesigned questionnaire was circulated among them after taking consent. The nurses' were informed that the participation was voluntary \& anonymous. The study was done from august 2012 to December 2012. The data was entered in Microsoft excel and SPSS 17 was used for analysis of the same. All data forms underwent scrutiny for logical inconsistencies, skip patterns \& missing values and errors were identified for correction. The percentages and their 95\% confidence intervals (CIs) have been being presented.

\section{Results :}

Analysis of data revealed that knowledge regarding biomedical waste rules, color coding of waste containers, segregation of waste at source, disinfection of hospital waste before disposal $\&$ transmission of diseases through biomedical waste was very good among the nursing staff of this hospital. The values being more than $70 \%$. The details are depicted in table 1 .

The attitude of the nurses towards segregation of infectious and non infectious wastes was positive with $80 \%$ in favor of implementation. 
Regarding practices related to biomedical wastes $70 \%$ practiced the disposal in specified color coded bins, while as $72 \%$ made disposal of sharps in puncture proof containers but only $30 \%$ were reporting the injuries due to improper disposal of sharps. The details are depicted in table 2.

Table 1: Knowledge regarding biomedical waste management

\begin{tabular}{|l|l|l|}
\hline Knowledge regarding & $\mathrm{N}=50$ & $\mathrm{c} .1(95 \%)$ \\
\hline Biomedical waste management rules & $46(92 \% 0$ & $81.6-97.2$ \\
\hline Color coding for waste containers & $46(92 \%)$ & $81.6-97.2$ \\
\hline Segergration of waste at source & $41(82 \%)$ & $70.4-90.9$ \\
\hline Disinfection of hospital waste before Disposal & $37(74 \%)$ & $61.8-83.9$ \\
\hline $\begin{array}{l}\text { Transmission of diseases through Biomedical } \\
\text { waste }\end{array}$ & $45(90 \%)$ & $80.1-96.2$ \\
\hline
\end{tabular}

Table 2: Practices of nurses regarding biomedical waste

\begin{tabular}{|l|l|l|}
\hline & $\mathrm{N}=50$ & $\mathrm{c} .1(95 \%)$ \\
\hline Disposal in specified color coded containers & $35(70 \%)$ & $57.3-80.9$ \\
\hline Disposal of sharps in puncture proof containers & $36(72 \%)$ & $56.8-81.1$ \\
\hline $\begin{array}{l}\text { Reporting of injuries due to improperly } \\
\text { disposed sharps }\end{array}$ & $15(30 \%)$ & $18.8-43.2$ \\
\hline
\end{tabular}

\section{Discussion}

Various cross sectional studies have been done on the same as mentioned in our study ${ }^{(6,7,10)}$. Knowledge about biomedical waste management is consistent with other studies on the subject ${ }^{(7,8,9)}$. The practice of non-reporting of injuries due to sharps is low among nurses of this hospital. Consistent figures have also been shown by other studies ${ }^{(7,10,11,12)}$. Low reporting in our study is possibly due to unawareness about formal system of injury reporting due to sharps in a health care setting.

\section{Conclusion and recommendations.}

Regular training and awareness generation activities among the nursing staff needs to be held to increase the knowledge, attitude and practices up to $100 \%$ level. Nursing protocol should be made for handling infectious as well as non-infectious wastes. Adequate supplies and equipments should be available in all the departments to take care of waste properly. A mechanism of injury reporting in the hospital needs to be established.

\section{Biobliography:}

[1]. Das SK, Sushant P, Jayaram K : A TQM approach to implementation of handling and management of Hospital wastes in TATA main Hospital; issued by Hospital waste management committee, T.M.H.2001:11-12(1-2):75-78

[2]. Pruss A, Circouit E, Rushbrook P: safe management of wastes from health care activities; WHO199 pg 2

[3]. Patil AD, Shekhar AV. Health Care Waste management in India. J.Enviorn Mange 2001;63:211-20

[4]. Ministry of Environment and forest notification on the Bio- Medical Waste (Management and Handling) Rules, 1998

[5]. Plianbangchang PH. "A Report on Alternative Treatment and Non-Burn Disposal Practices"; Safe Management of Bio-medical Sharps Waste in India. W.H.O. Publication.

[6]. Rao PH. Report: Hospital waste management--awareness and practices: A study of three states in India. Waste Manage Res

[7]. 2008;26:297-303

[8]. Mathur V, Dwivedi S, Hassan MA, Misra RP. Knowledge, attitude, and practices about biomedical waste management among healthcare personnel: A cross-sectional study. Indian J Community Med 2011;36:143-5.

[9]. Pandit NB, Mehta HK, Kartha GP, Choudhary SK. Management of bio-medical waste: Awareness and practices in a district of

[10]. Gujarat. Indian J Public Health 2005;49:245-7.

[11]. Saini S, Nagarajan SS, Sarma RK. Knowledge; Attitude and Practices of Bio-Medical Waste Management Amongst Staff of a Tertiary Level Hospital in India. J Acad Hosp Adm 2005;17:2.

[12]. Madhukumar S, Ramesh G." study about awareness and practices about health care wastes management among hospital staff in a medical college Hospital, Banglore , Int J Basic Med sci April 2012, 3(1):7-11

[13]. Stein AD, Makarawo TP, Ahmad MF. A survey of doctors' and nurses' knowledge, attitudes and compliance with infection control guidelines in Birmingham teaching hospitals. J Hosp Infect 2003;54:68-73.

[14]. Nagaraju B, Padmavathi GV, Puranik DS, et al. "A study to assess the knowledge and practice on bio-medical waste management among the health care providers working in PHCs of Bagepalli Taluk with the view to prepare informational booklet", Int J Med Biomed Res 2013;2(1):28-35 